\title{
EXERCÍCIOS DE ESCRITA AUTORAL EM SALA DE AULA: AS SEQUÊNCIAS DIDÁTICAS COMO ESTRATÉGIAS DE DESENVOLVIMENTO DE PRÁTICAS DISCURSIVAS NO ENSINO FUNDAMENTAL
}

\author{
WRITING EXERCISES IN THE CLASSROOM: \\ THE DIDACTIC SEQUENCES AS STRATEGIES TO DEVELOP \\ DISCURSIVE PRACTICES IN ELEMENTARY EDUCATION
}

\author{
Angela Machado de Paula ${ }^{1}$ \\ Ana Maria Esteves Bortolanza ${ }^{2} *$
}

\section{Resumo}

Este trabalho, parte de uma pesquisa (2015) realizada com alunos de $4^{\circ}$ ano do ensino fundamental, de uma escola pública no interior de Minas Gerais, analisa indícios da escrita autoral no processo de ensino e aprendizagem do gênero conto, evidenciando os processos de interação na sala de aula, a partir dos gêneros discursivos como organizadores das ações com a linguagem verbal no processo de ensino e aprendizagem da escrita. Tem como procedimentos metodológicos observações e um experimento pedagógico organizado em atividades de sequências didáticas com os elementos estruturadores do conto. Fundamenta-se em concepções de Vigotski e seus colaboradores, Bakhtin, Dolz e Schneuwly. Os resultados mostram indícios de reprodução e de criação do gênero conto pelos alunos no processo de constituição de sua autoria, desvelando em suas produções textuais conhecimentos de mundo, linguísticos, textuais. Conclui-se que compete ao professor ensinar as estratégias da escrita autoral, ao identificar e utilizar adequadamente as ferramentas adequadas para o ensino dos gêneros textuais por meio de sequências didáticas que possibilitem aos alunos apropriarem-se dos elementos estruturadores do conto com foco na constituição autora, de maneira a desenvolverem práticas discursivas.

Palavras-chave: Práticas discursivas. Constituição autora. Apropriação da escrita. Sequências didáticas.

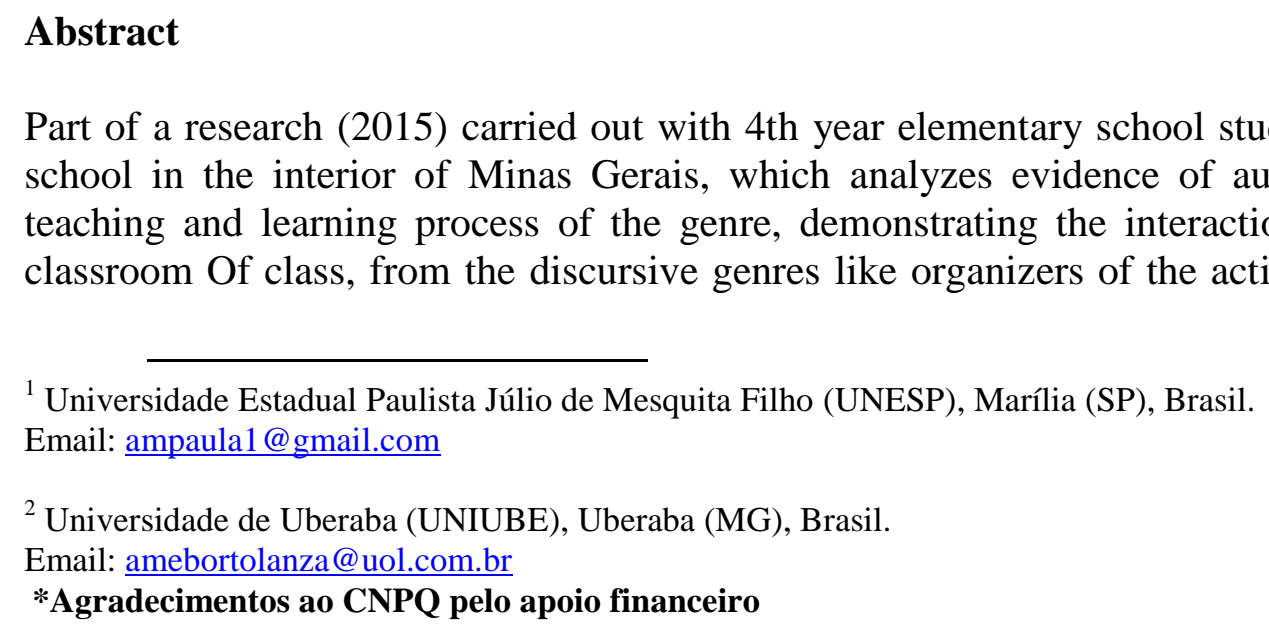

\footnotetext{
${ }^{1}$ Universidade Estadual Paulista Júlio de Mesquita Filho (UNESP), Marília (SP), Brasil. Email: ampaula1@gmail.com

${ }^{2}$ Universidade de Uberaba (UNIUBE), Uberaba (MG), Brasil.

Email: amebortolanza@uol.com.br

*Agradecimentos ao CNPQ pelo apoio financeiro
}

Part of a research (2015) carried out with 4th year elementary school students from a public school in the interior of Minas Gerais, which analyzes evidence of author writing in the teaching and learning process of the genre, demonstrating the interaction processes in the classroom Of class, from the discursive genres like organizers of the actions with the verbal

Revista Devir Educação, Lavras, vol.2, n.1, p.83-102, jan./jun., 2018. 


\section{DEVIR EDUCAÇÃO}

ISSN: 2526-849X

language in the process of teaching and learning of the writing. It has as methodological procedures observations and a pedagogical experiment organized in activities of didactic sequences with the structuring elements of the story. It is based on conceptions of Vygotsky and his collaborators, Bakhtin, Dolz and Schneuwly. The results show signs of reproduction and of the creation of the genre as tale by the students in the process of constitution of their authorship, revealing in their textual productions world knowledge, linguistic, textual. It is concluded that it is the teacher's responsibility to teach the strategies of author writing by properly identifying and using the appropriate tools for the teaching of textual genres through didactic sequences that enable students to appropriate the structuring elements of the story with a focus on the author's constitution, to develop discursive practices

Keywords: Discursive practices. Author's constitution. Writing appropriation. Didactic sequences.

\section{Introdução}

O processo de apropriação da cultura humana é resultado da atividade cultural sobre os objetos e o mundo circundante mediado pela comunicação. Em outras palavras, é a relação com os objetos do mundo, mediado por outros homens, que possibilita ao indivíduo apropriarse da cultura e humanizar-se. Para Leontiev (2004) esse processo é a educação, principal motor de transmissão e apropriação da história cultural dos homens, processo de transmissão e assimilação da cultura produzida historicamente, sendo por meio dela que os indivíduos se educam ao herdarem e assimilarem a cultura. Essa concepção de educação implica um grande desafio à escola e aos educadores, pois é um cenário privilegiado de oportunidades dos sujeitos que a ela se integram. Uma das fontes de humanização na escola são as práticas discursivas no contexto das interações entre alunos que se constituem autores pela linguagem. A constituição da autoria é parte desse processo ao desenvolver o aluno e possibilitar-lhe constituir-se como sujeito de suas ações verbais.

Entretanto, no atual cenário educacional, as avaliações institucionais como SAEB, PROALFA, SIMAVE, PISA, ENEM, bem como estudos publicados sobre o domínio da escrita por alunos do ensino fundamental, mostram que os alunos na educação básica apresentam dificuldades para ler e escrever com proficiência, quando deveriam constituir-se bons autores e leitores no processo de escolarização.

Como situar essa problemática? Entendemos que, uma das questões relevantes para enfrentarmos as dificuldades de escrita que os alunos apresentam cada vez mais é compreendermos como aprendem a escrever, especificamente, como aprendem a produzir textos posicionando-se como sujeitos de linguagem, autores de sua palavra.

Revista Devir Educação, Lavras, vol.2, n.1, p.83-102, jan./jun., 2018. 


\section{Q DEVIR EDUCAÇÃO}

ISSN: 2526-849X

$\mathrm{Na}$ busca dessas respostas, investigamos como alunos do $4^{\circ}$ ano do ensino fundamental de uma escola pública situada no Triângulo Mineiro, interior do estado de Minas Gerais, constituem-se autores de textos narrativos por meio de sequências didáticas tendo como corpus contos latino-americanos. A pesquisa, de caráter qualitativo foi realizada em 2015, por meio de observações e um experimento pedagógico com atividades planejadas em sequências didáticas para trabalhar os elementos estruturadores do conto.

O estudo se respalda em fundamentos teóricos que explicam a aprendizagem da escrita enfatizando a constituição da autoria do aluno no processo de apropriação da escrita por meio de textos. Os principais autores que subsidiam a análise dos dados são Vigotski e Bakhtin que possibilitam explicar o processo de apropriação da escrita, dialeticamente construído por meio da linguagem entre indivíduo (subjetividade) e sociedade (objetividade). É a linguagem que medeia a relação dialógica do sujeito com o outro e com o mundo, portanto ela é um instrumento semiótico. Sem linguagem não há possibilidade de significar o mundo, a si mesmo e o outro, por conseguinte constituir sujeito autor, produtor de textos. Outros autores como Dolz e Schneuwly (2011) contribuem para o ensino da escrita de textos por meio de sequências didáticas.

A investigação partiu de observações, num primeiro momento, em que analisamos as atividades desenvolvidas pela professora da turma. A seguir foi realizada uma atividade exploratória com a finalidade de os alunos identificassem alguns gêneros textuais e verificássemos seus conhecimentos prévios, conhecimentos de mundo e conhecimentos linguísticos sobre a temática. No segundo momento, foi desenvolvido um experimento pedagógico por meio de sete sequências didáticas que tiveram como objetivo que os alunos se apropriassem da escrita de contos. Após as sequências didáticas trabalhadas com os elementos estruturadores do conto, os alunos produziram em dupla um conto como produto final do experimento pedagógico. $\mathrm{Na}$ atividade inicial, de caráter diagnóstico, destacamos os elementos constitutivos do conto: sequência de ações, personagens, tempo, espaço, narrador, elemento mágico e desfecho.

O corpus escolhido para a pesquisa faz parte de uma coleção de contos tradicionais e populares, publicados em coedição latino-americana, pelo Centro Regional para o Fomento do Livro na América Latina e no Caribe e Intercâmbios Culturais e Internacionais da UNESCO, na década de 1980-1990. Foi realizado um levantamento dos contos por localização geográfica (16 países) e pelas temáticas abordadas (8 temas) da coleção (8 livros).

Revista Devir Educação, Lavras, vol.2, n.1, p.83-102, jan./jun., 2018. 


\section{OO DEVIR EDUCAÇÃO}

ISSN: 2526-849X

São eles: "Os contos populares para crianças da América Latina", "Como surgiram os seres e as coisas", "Contos de animais fantásticos", "Contos de lugares encantados", "Contos e lendas de amor", "Contos de artimanhas e travessuras", "Contos de assombração", "Contos de piratas, corsários e bandidos".

\section{O processo de apropriação da escrita e a formação da autoria: alguns princípios teóricos}

A grande maioria dos métodos e teorias educacionais baseia-se na concepção de que "os conhecimentos científicos não têm nenhuma história interna, isto é, não passam por nenhum processo de desenvolvimento, sendo absorvidos já prontos mediante um processo de compreensão e assimilação". (VIGOTSKI, 2010, p. 245). O autor explica que para se criar métodos eficazes para a instrução das crianças em idade escolar é importante compreender o desenvolvimento dos conceitos científicos no pensamento infantil, para compreender o que acontece na mente da criança quando aprende conceitos, sobretudo para entender qual é a relação existente entre assimilação da informação e desenvolvimento interno de um conceito científico na consciência da criança.

Nessa perspectiva, Vigotski (2010, p. 260) afirma que “[...] os conceitos científicos não são assimilados nem decorados pela criança, não são memorizados, mas surgem e se constituem por meio de uma imensa tensão de toda a atividade do seu próprio pensamento".

Para o autor, a aprendizagem é:

[...] uma das principais fontes de desenvolvimento dos conceitos infantis e poderosa força orientadora desse processo. [...] a aprendizagem é, na idade escolar, o momento decisivo e determinante de todo o destino do desenvolvimento intelectual da criança, inclusive do desenvolvimento dos seus conceitos [...] os conceitos científicos de tipo superior não podem surgir na cabeça da criança senão a partir de tipos de generalização elementares e inferiores preexistentes, nunca podendo inserir-se de fora na consciência da criança. (VIGOTSKI, 2010, p. 262).

Os conceitos, portanto, se desenvolvem sob condições internas e externas totalmente diferentes, dependendo do fato de se originarem no processo de aprendizagem escolar ou da experiência pessoal da criança. Aqui temos um primeiro princípio teórico essencial para o processo de ensino e aprendizagem da escrita. A criança aprende na vida e na escola. Quando entra na escola, já tem conhecimentos sobre a escrita, os textos e sua funcionalidade social, 


\section{OD DEVIR EDUCAÇÃO}

ISSN: 2526-849X

pois já interage com os adultos e com outras crianças, assimilando diferentes práticas discursivas da língua materna.

Para Vigotski (2010, p. 322), a relação entre ensino e aprendizagem é vista como condição para o desenvolvimento das funções psicológicas superiores, pois se adiantando ao desenvolvimento, impulsiona a criança para a aquisição de "habilidades numa área específica antes de aprender a aplicá-los de modo consciente e arbitrário." Portanto, o desenvolvimento e a aprendizagem possuem sua própria organização e em ambos os processos as curvas não coincidem, "há sempre uma discrepância e nunca paralelismo entre o processo de aprendizagem escolar e o desenvolvimento das funções correspondentes". Assim, a aprendizagem é um processo que se realiza em tempos, espaços e relações, planejado pelo professor no processo letivo, diferentemente do desenvolvimento que segue outra lógica.

Um bom exemplo é a aprendizagem da escrita de textos. Quando a criança começa a aprender a ler e a escrever ainda não possui as funções psíquicas para essa aprendizagem, paradoxalmente, é a aquisição da escrita que impulsionará o desenvolvimento de suas funções psicológicas superiores. Trata-se de um processo de superação das contradições entre aprender para desenvolver e desenvolver-se para aprender. Entendemos que a apropriação da escrita por meio dos gêneros discursivos começa desde o contato da criança com os primeiros registros escritos.

A aquisição da escrita alavanca o desenvolvimento da criança e, simultaneamente, seu desenvolvimento permite-lhe apreender a escrita. Trata-se de um princípio vigotskiano fundamental para compreendermos como a criança aprende a escrever, e, consequentemente como ela pode ser ensinada.

Diferentemente da linguagem oral, tanto em sua estrutura como funcionamento, a linguagem escrita não é a tradução da fala, por isso não pode ser ensinada como uma simples técnica, de decodificação e codificação de sons e letras. Seu ensino exige uma dupla abstração: a ausência de som e de interlocutor, por isso, o aluno precisa pensar como representar na escrita os símbolos sonoros que aprendeu naturalmente, "uma simbolização de segundo grau, [...] tão difícil em relação à linguagem oral, como é [...] a álgebra em relação à aritmética. (VIGOTSKI, 2001, p. 230).

$\mathrm{Na}$ fala, o diálogo pressupõe que os interlocutores tenham ambos um conhecimento suficiente do assunto, tornando possível sua abreviação. Também pressupõe a percepção visual do interlocutor, suas expressões faciais, seus gestos e a entonação que facilitam uma 
compreensão diferenciada do significado das palavras. O conhecimento do sujeito e a transmissão imediata do pensamento pela entonação facilitam a abreviação da linguagem falada e, assim, a comunicação verbal.

A linguagem escrita possui uma outra natureza, desprovida de som e de um interlocutor face a face, “[...] a linguagem escrita é a forma de linguagem mais prolixa, exata e desenvolvida. Nela temos de transmitir por palavras o que na linguagem falada se transmite por entonação e pela percepção imediata da situação". O diálogo implica o enunciado imediato, uma vez que, segundo Vigotski (2010, p. 456) é "um discurso constituído de réplicas". Já o monólogo é uma complexidade composicional, que introduz uma elaboração linguística lenta e consciente.

No processo de assimilação da linguagem escrita, a criança precisa se desligar do aspecto sensorial da linguagem oral e substituir palavras por imagens de palavras. Como se trata de uma linguagem sem som real, exige uma simbolização de imagens sonoras por meio de signos escritos, ou melhor, uma representação simbólica de segunda ordem. A linguagem escrita exige que a criança entre no plano abstrato mais elevado da linguagem, pois se trata de uma linguagem "abstrata, que não utiliza palavras, senão ideias de palavras". (VIGOTSKI, 2001, p. 229) $)^{3}$.

Este princípio teórico é crucial para compreendermos o papel da função simbólica no processo de ensino e aprendizagem da escrita. Até chegar à escrita, a criança percorre um longo caminho, passa dos gestos, para garatujas e desenhos, pelas brincadeiras, pela fala e então chega à escrita simbólica.

Se pretendermos formar a atitude autora do aluno no ensino fundamental, as práticas discursivas trabalhadas em sala de aula precisam focar no processo de apropriação da escrita e sua relação com o desenvolvimento do aluno. Nesse sentido, a instrução escolar alavanca o desenvolvimento do aluno ao partir de um ensino intencionalmente planejado para essa finalidade.

Enfim, a questão da formação da atitude autora precisa ser tomada no espaço escolar como um posicionamento do aluno-sujeito que assume a responsabilidade por sua palavra, pois a característica fundamental desse processo é a constituição de sujeitos de linguagem que por meio dela se constituem nas interações verbais, isto é, por meio dos gêneros discursivos ou textuais. Segundo Bakhtin (1997, p. 279) "qualquer enunciado considerado isoladamente

\footnotetext{
${ }^{3}$ Tradução nossa.
} 


\section{Q DEVIR EDUCAÇÃO}

ISSN: 2526-849X

é, claro, individual, mas cada esfera de utilização da língua elabora seus tipos relativamente estáveis de enunciados, sendo isso que denominamos gêneros textuais".

Rodeados por uma infinidade de gêneros textuais, produzi-los parece tarefa fácil para alguns, mas extremamente complexa para outros. Por isso, organizar um ensino intencional em que alunos sejam capazes de reconhecer, produzir e empregar diferentes gêneros textuais é uma tarefa que cabe à escola assumir ao focar a constituição autoras de seus alunos. À medida que os alunos reconhecem e produzem gêneros discursivos vão simultaneamente constituindo-se autores de seus textos.

Nessa perspectiva, cabe à escola planejar e executar o ensino da língua materna por meio dos gêneros textuais, trabalhando a língua viva, para que seus alunos constituam-se autores proficientes, pois para Bakhtin (1997, p. 285) "a língua escrita corresponde ao conjunto dinâmico e complexo constituído pelos estilos da língua, cujo peso respectivo e a correlação, dentro do sistema da língua escrita, se encontram num estado de contínua mudança".

Os gêneros textuais como práticas sociais não se separam das relações e práticas nas quais estão inseridos. Para tanto, é preciso que a escola traga a diversidade de gêneros textuais e suportes que circulam na sociedade para suas atividades pedagógicas, a fim de que os alunos tenham acesso e se apropriem das práticas discursivas. Empregamos o termo suporte de texto, de acordo com Marcuschi (2003, p. 8) como "um locus físico ou virtual" que sustenta um texto, ou seja, "que serve de base ou ambiente de fixação do gênero materializado como texto".

O ensino da escrita de textos organizado em sequências didáticas de diferentes gêneros textuais em múltiplos suportes cumpre com esse objetivo. Trazemos as contribuições teóricas de Schneuwly e Dolz (2011, p. 65) que mostram o gênero não apenas como instrumento de comunicação, mas também como objeto de ensino-aprendizagem. Como objetos de ensino, os textos em diferentes gêneros precisam ser ensinados de forma sistemática, de maneira a colocar os alunos frente a práticas discursivas de linguagem que são histórica, social e culturalmente construídas e, assim, dar-lhes a possibilidade de aprendê-las e delas se apropriarem.

Ao tratarem sobre as sequências didáticas, Schneuwly e Dolz (2011, p. 96) afirmam que "As sequências visam ao aperfeiçoamento das práticas de escrita e de produção oral e estão principalmente centradas na aquisição de procedimentos e de práticas". Portanto, as 


\section{Q DEVIR EDUCAÇÃO}

ISSN: 2526-849X

sequências didáticas têm como objetivo fazer com que o aluno domine melhor um gênero por etapas, trabalhando o processo de construção do gênero discursivo com a finalidade de os alunos apropriarem-se dos conceitos necessários para sua utilização, seja na linguagem oral ou na escrita. "As sequências didáticas servem, portanto, para dar acesso aos alunos a práticas de linguagem novas ou dificilmente domináveis" (SCHNEUWLY; DOLZ, 2011, p. 83).

\section{As atividades de produção textual de contos por meio de sequências didáticas}

Num primeiro momento foi explicada aos alunos a importância de conhecer os contos maravilhosos da América Latina, argumentando que as crianças brasileiras conhecem vários contos europeus como "O gato de botas", "A lâmpada de Aladim”, “Ali babá e os quarenta ladrões", entre outros, mas pouco ou nada conhecem sobre os contos do continente latinoamericano, de países vizinhos do Brasil. Também nos preocupamos em trabalhar a multiculturalidade presente nos contos escolhidos.

Como os alunos não tinham uma ideia clara de continente e de país, e também não conheciam os contos da América Latina, para cada nova sequência didática, levávamos o mapa da América Latina, de forma a contextualizar o conto a ser trabalhado. Na viagem imaginária que havíamos proposto aos sujeitos da pesquisa, indicávamos o país onde o conto se originara, sempre contextualizando em relação ao nosso país e ao continente sulamericano. Assim, os alunos foram se apropriando, também, do contexto geográfico e histórico-cultural dos países visitados por meio dos contos trabalhados. Isso fez com que as crianças se motivassem para saber mais sobre os países de nosso continente. Antes de iniciarmos as atividades linguísticas e textuais de escrita, apresentávamos slides, fotos e informações sobre o país ao qual o conto a ser trabalhado pertence.

No experimento pedagógico foram desenvolvidas, com os sujeitos da pesquisa, sete sequências didáticas com os elementos constituintes do conto. Foram eles: "Uapé" (Argentina), “A vara de São Marmelo" (Peru), "Dona raposa e os peixes" (Venezuela), "O rei da folhagem" (Nicarágua), "O cavalinho de sete cores" (Guatemala), "Maria Angula" (Equador) e "As Lágrimas de Potira" (Brasil).

O conceito de conto foi explorado na primeira sequência didática trabalhada. Em seguida, propusemos às crianças a primeira viagem imaginária para a Argentina, para conhecer o conto "O Uapé". Dois elementos constitutivos do conto foram destacados: as personagens e a sequência de ações.

Revista Devir Educação, Lavras, vol.2, n.1, p.83-102, jan./jun., 2018. 


\section{Q DEVIR EDUCAÇÃO}

ISSN: 2526-849X

A segunda sequência didática consistiu em uma viagem imaginária para o Peru, por meio do conto "A vara de São Marmelo". O objetivo foi identificar e descrever as personagens. Antes de encerrar a sequência, os alunos elaboraram uma descrição sobre as personagens do conto. Para ajudar nesse processo de escrita, distribuímos os alunos em duplas, um aluno mais experiente atuando como escriba para que compartilhasse com o colega menos experiente o processo de criação e registro do conto. A maior parte das duplas de alunos maioria copiou a descrição de Casimiro e de Filomena do texto, embora tivéssemos orientado que escrevessem com suas próprias palavras. Esse comportamento se explica pelo fato de os alunos estarem acostumados a fazer cópias da lousa e do livro didático, prática pedagógica que constatamos nas observações. No final pedimos para algumas duplas lerem em voz alta para a turma. Um recurso utilizado para identificação das personagens foi grafar o nome de cada uma em caixa alta e grifá-las em negrito, para destacar de outras palavras do texto.

$\mathrm{Na}$ terceira sequência didática, os alunos realizaram uma viagem imaginária pela Venezuela, por meio do conto "A dona Raposa e os peixes". No conto, o tempo e o espaço foram trabalhados por meio das cores azul (tempo) e vermelho (espaço), facilitando a identificação desses elementos e suas relações. Na realização dessa sequência didática, as crianças construíram também uma linha do tempo (2000-2013) em um grande painel na lousa, período da vida dos próprios alunos da pesquisa para que pudessem assinalar fatos que marcaram esse tempo. O objetivo foi mostrar a relação entre tempo e espaço partindo dos lugares em que eles nasceram e das datas de nascimento.

$\mathrm{Na}$ quarta sequência didática, a finalidade foi trabalhar a ideia de narrador. Para isso, depois da leitura do conto "O rei da folhagem" (Nicarágua) e da exploração oral sobre o conceito de narrador em $3^{\mathrm{a}}$ pessoa, apresentamos também outro texto com narrador em $1^{\mathrm{a}}$ pessoa. Os alunos concentraram-se bastante no momento da leitura silenciosa e se motivaram a realizar a leitura compartilhada em voz alta para todos.

Na quinta sequência didática, os alunos continuaram a viagem imaginária, tendo como país de destino a Guatemala e o conto "O cavalinho de sete cores". O objetivo desta sequência foi trabalhar o objeto mágico: o cavalinho que foi desenhado de diferentes maneiras e com grande riqueza de detalhes. O que mais os encantou, em todas as sequências didáticas, foi o elemento mágico. 


\section{OO DEVIR EDUCAÇÃO}

ISSN: 2526-849X

Na sexta sequência didática, a viagem imaginária foi para o Equador. O conto lido para as crianças "Maria Angula" possibilitou que trabalhássemos o desfecho da narrativa. $\mathrm{O}$ conto foi apresentado em um cartaz sem o desfecho. Depois da leitura e a exploração do texto, instigamos os alunos a criarem um novo desfecho, coerente com o conto. Só depois de terem criado diferentes desfechos para o conto é que apresentamos o desfecho original do conto.

Trazemos dois dos desfechos criados. O primeiro fecha o conto na perspectiva de uma história de terro, enquanto o segundo traz um elemento surpresa, ambos bastante criativos.

Marina: Que o defunto pegou as tripas e o estômago da Maria Angula. (2013).

Renata: Que ela sentiu o pé e quando ela abriu os olhos era a Mercedes, a cozinheira que ela sempre pedia. (2013).

Na sétima sequência didática, tendo como objetivo trabalhar todos os elementos da narrativa/conto, retomamos todas as sequências didáticas para fazer uma síntese dos elementos constitutivos do conto. Com o conto "As lágrimas de Potira" (Brasil), encerramos a viagem imaginária com os alunos. Após a leitura e exploração oral do conto, explicamos que iriam estudar o conto inteiro, ou seja, identificar todos os elementos constitutivos da narrativa/conto e seus respectivos conceitos.

O diálogo que se segue mostra que os alunos identificaram todos os elementos estruturadores de um conto.

Pesquisadora: Para iniciarmos eu queria dizer que a gente vai analisar o conto inteiro. Vamos começar então pelas ações.

Marina: Muito antes dos brancos atingirem os sertões, havia muitas tribos indígenas e em uma dessas tribos ...

Pesquisadora: $O$ que aconteceu em uma dessas tribos? Fala Hernane.

Hernane: A Potira e o Itagiba se gostavam muito, aí quando a Potira teve idade de casamento e Itagiba ele era um guerreiro, aí uma outra tribo invadiu a tribo deles, aí teve uma guerra, aí o marido de Potira foi pra guerra, aí quando chegou todos os guerreiros aí anunciou que o marido de Potira tinha morrido, ela chorou muito. Aí no final mostra que as lágrimas dela se transformavam em ouro.

Quase todos: Em diamantes.

Pesquisadora: Isso, muito bem. Então, quais são as personagens?

Quase todos: Potira, Itagiba e Tupã.

Pesquisadora: Isso, no texto fala das características da Potira?

Quase todos: Fala.

Pesquisadora: Como que ela era? Quem gostaria, José Leonardo.

José Leonardo: Valente...

Pesquisadora: A Potira, fala Ana Cassia.

Revista Devir Educação, Lavras, vol.2, n.1, p.83-102, jan./jun., 2018. 


\section{DEVIR EDUCAÇÃO}

ISSN: 2526-849X

Ana Cassia: Ela era uma menina contemplada por Tupã com a formosura das flores.

Pesquisadora: Isso, muito bem, e Itagiba? Como ele era? Marina.

Marina: Forte e valente.

Pesquisadora: Um jovem forte e valente, muito bem. Bom, onde que acontece essa história? Em que lugar, Gabriel?

Gabriel: Numa tribo.

Pesquisadora: Numa tribo indígena, muito bem. Quando? Marina.

Marina: Antes dos brancos atingirem os sertões de Goiás.

Pesquisadora: Isso! Tem um narrador? Ele participa da história ou ele fica escondido? Tem elemento mágico?

Quase todos: Tem.

Pesquisadora: Ana Cassia, qual é o elemento mágico?

Ana Cassia: As lágrimas de Potira.

Pesquisadora: As lágrimas de Potira que se transformam...

Quase todos: Diamantes.

Pesquisadora: [...] Bom e qual que é o desfecho dessa história? Eu coloquei de cor diferente. Quem gostaria de falar, como que termina essa história? Luciane.

Luciane: Dizem que Tupã, condoído com tanto sofrimento, transformou suas lágrimas em diamantes, para perpetuar a lembrança daquele amor.

A identificação dos elementos estruturadores do conto evidencia que as atividades de sequências didáticas foram metodologicamente adequadas para que os alunos se apropriassem desse gênero textual em suas produções textuais.

Após trabalharmos as sete sequências didáticas, os alunos produziram em duplas um texto em que deveriam estar presentes os elementos constitutivos do conto. A oitava e última atividade oportunizou aos alunos produzir seus próprios contos, como sujeitos autores, no exercício da escrita autoral. No primeiro momento, as duplas planejaram entre si quais seriam as personagens, as ações, o elemento mágico, onde se passaria a história, quando, que tipo de narrador e como seria o desfecho. Depois, produziram os rascunhos dos textos, e à medida que iam terminando, recebera uma folha pautada para o registro do texto produzido por cada dupla de alunos. Nessa atividade, ao trabalhar com o roteiro para a criação do conto maravilhoso, a preocupação foi que os sujeitos da pesquisa elaborassem rascunhos mentais, como expõe Vigotski (2010) ao tratar sobre o processo criativo da criança.

Destacamos primeiramente os elementos sobre o espaço dos contos criados. Alguns contos se passam em lugares fora da realidade conhecida, característicos de contos de fadas como: "terra do nunca"; "torre abandonada"; "mansão assombrada". Outros, porém são lugares reconhecíveis ou familiares, característicos dos contos maravilhosos como: “jardim”, "floresta", "praia de Cancun", "faroeste", "bosque", "em um bairro", "em um campo de flores", dentre outros. Já em relação ao tempo, o que prevaleceu foi um tempo 


\section{Q DEVIR EDUCAÇÃO}

ISSN: 2526-849X

cronologicamente curto como "de manhã", "à tarde", "à noite", "em uma noite chuvosa", "em um sábado", "em um dia bem frio".

Quanto às personagens, verificamos que em sete contos aparecem personagens dos contos de fadas como "rei", "rainha”, "princesa", "bruxa”, "fada", "príncipe”, “dragão". Em quatro contos as personagens são seres humanos comuns, alguns grafados em inglês, outros lembram artistas: "Tereza", "Carla", "Roberta", "Elisa", "Eduardo", "Bianca", "Kawany", "Gabriel”, "Caio Castro", "Taylor Swift", "Renato Jonequine”, "Demi Lovato". Em outro conto aparece o "Senhor Assombrado" e o "Senhor Monstro". Temos também personagens com funções sociais como em "xerife" e "camponesa". E, por fim, personagens que trazem animais falantes como "urso", "borboleta", "rato".

Analisando as características das personagens, constatamos que em três rascunhos, as duplas não as caracterizaram. Em outros rascunhos, encontramos personagens com diferentes características, obedecendo aos padrões sociais estabelecidos como em: "mulher de cabelos longos e loiros", "de olhos azuis, magra, muito bonita e patricinha", outra "de cabelos até os ombros e castanhos, baixa e um pouco gorda, e normal", e uma terceira de "cabelos pretos que batem no peito e com mechas vermelhas, meio roqueira e magra". Algumas personagens são características de contos de fadas como em: "dragão vermelho, de dentes afiados e invencível', "princesa bonita e simpática", "príncipe forte, valente e muito bonito", "bruxa, mulher muito má que pega o poder das fadas", "fadas que trabalham para a bruxa", "dinossauro preguiçoso", "cavalheiro valente". Personagens que são animais: "urso branco", "rato marrom", "leopardo veloz", "leão feroz”. Personagens que são característicos dos desenhos animados e jogos online: "guerreiro alto e forte", "Senhor Assombrado de dentes muito afiados, casado com a Senhora Monstro". Personagens que são característicos das telenovelas e cantores americanos: "Caio Castro" (policial), "Renato Jonequine” (ator), "Swift Taylor" (cantora), "Demi Lovato" (cantora). Personagens com nomes e características dos colegas da turma: "Kawany, uma aluna, menina criativa e doce", " Gabriel, um rapaz preguiçoso que fala muito".

Sobre os elementos mágicos, apareceram dois animais, "um cavalo" e "uma borboleta", remetendo-nos aos animais fantásticos dos contos maravilhosos. Também apareceram elementos mágicos como "varinha", "pó doce", "espada de ouro", que nos reportam aos contos de fadas. Surgiu ainda um "vampiro", associado aos contos de 
assombração, "uma pedra" que remete aos contos populares, "um caderno mágico", "baú mágico" e "brinquedos mágicos", elementos comuns em histórias infantis.

Sete rascunhos não apresentavam o desfecho da história. Isso evidencia que, no momento do planejamento do texto, os alunos tiveram alguma dificuldade para elaborar o final da história, deixando este elemento para criar depois, no desenrolar da escrita do conto. O desfecho foi o elemento que demandou mais tempo das duplas para ser criando em relação aos outros elementos. Isso se explica por ser o fechamento do conto, momento da escrita em que deveria ser coerente com as ações, as personagens, o tempo, o espaço, o elemento mágico, para que o conto fosse verossímil.

Constatamos que as quatro duplas que planejaram o desfecho trouxeram as formas canônicas dos contos de fadas tais como "eles viveram felizes para sempre". Somente em um dos rascunhos encontramos um desfecho diferente dos cânones estabelecidos, "então os monstros derreteram e morreram e, em outro desfecho a varinha cai no chão e a princesa pega e transforma a bruxa em pedra e eles se casam".

Apresentada as sequências didáticas e o processo de como os alunos elaboraram suas narrativas trazendo os elementos estruturadores do conto, passamos à análise dos processos de criação e reprodução na produção de textos com foco no processo da constituição autora.

\section{A constituição autora: processos de criação e reprodução na produção textual}

Quanto às marcas de autoria, pautamos pelas variadas formas de estabelecer o processo de autorar no qual a criação e a reprodução assumem lugar de destaque para Vigotski (2009), ao explicar que não apenas conservamos e reproduzimos nossas experiências anteriores, mas combinamos e reelaboramos, criando novas situações ou algo novo. Também buscamos o pensamento bakhtiniano para compreender as formas de apropriação e reestruturação dos enunciados alheios presentes nas narrativas dos alunos, entendendo os textos como enunciados repletos de dizeres como afirma Bakhtin (1997).

A partir desses fundamentos vigotskianos e bakhtinianos, identificamos os seguintes indícios em fragmentos de contos produzidos pelos alunos, no processo de constituição de autoria:

a) os autores reproduzem a forma canônica do conto de fada: 


\section{OO DEVIR EDUCAÇÃO}

ISSN: 2526-849X

Era uma vez uma menininha que acabara de nascer em um castelo, era a princesa do reino... (Osório e Marina)

A forma canônica se repete quando a personagem protagonista é raptada pela bruxa. Mas, diferentemente dos contos de fadas, a bruxa não enfeitiça a princesa para cair num sono profundo, a prende na torre para que fique trabalhando.

Passaram-se 18 anos e a menina cresceu, e a bruxa raptava todas as fadas do reino para trabalhar para ela, e se as fadas não quisessem trabalhar ela as matava com a varinha.

No conto "A Bela Adormecida", o príncipe enfrentou a floresta de espinhos que cresceu em torno do castelo. Aqui os autores reproduzem uma situação muito parecida, pois o príncipe enfrenta também um obstáculo, o dragão da torre.

Ainda em outro trecho do conto:

O príncipe chegou lá e deu uma facada no dragão e quando entrou já lutando com a bruxa, ele jogou a varinha para a princesa e ela quebrou a varinha que era o poder da bruxa e ela desapareceu.

Os autores reproduzem essa passagem do conto original, pois o príncipe também luta contra o dragão para salvar a princesa. Na reprodução do conto a dupla traz como eixo gerador a problemática existencial, isto é, a realização do herói diretamente ligada à união homem-mulher.

No final, a dupla fecha com um desfecho de acordo com os modelos canônicos "foram felizes para sempre", como podemos constatar em:

Quando o príncipe e a princesa saíram ele jogou uma bomba que destruiu a torre toda.

O príncipe e a princesa se casaram e foram felizes para sempre.

Vigotski (2009) explica que a essência da atividade reprodutiva está diretamente ligada à reprodução ou repetição de construções mentais anteriores, podemos entender que ao trazer formas canônicas do conto de fadas, os alunos reproduziram modelos dos contos de fadas que assimilaram na escola e fora dela. Embora a história seja recriação de um conto existente, isso não significa ausência de autoria. No exercício de imitar (VIGOTSKI, 2009), os alunos desenvolveram as estruturas da narrativa/conto com claros indícios de autoria.

Revista Devir Educação, Lavras, vol.2, n.1, p.83-102, jan./jun., 2018. 


\section{b) os autores reelaboram novos elementos criativos}

Nesse conto, os alunos-autores combinam e reelaboram de forma criativa novos elementos, escrevendo o conto que passamos a analisar.

Em uma bela manhã o xerife Guilherme estava calmamente andando a cavalo quando tomou um enorme susto ele viu um enorme grupo de bois correndo atrás dele e ele como era muito valente ele virou o seu cavalo e de repente os cascos do cavalo começaram a brilhar e ele começou a galopar mais rápido. (Gabriel e Marília).

\section{c) os autores produzem novas ideias e novos elementos criativos}

As ideias apresentadas no trecho que se segue nos parecem ideias novas e não a reelaboração de ideias existentes. O elemento mágico diferente e criativo - os cascos do cavalo - fazia o cavalo galopar mais depressa.

Foi quando ele viu uma jovem camponesa amarrada bem à frente dos bois gritando:

Socorro, socorro, socorro!

Ele deu uma esporada no seu cavalo Alazão e parou ao lado da camponesa e desceu rapidamente de seu cavalo desamarrou a camponesa e subiu-a no seu cavalo Ele gritou: Já Alazão. E começou a galopar.

\section{d) os autores reelaboram e combinam elementos novos}

Neste fragmento verificamos que os autores usam sua imaginação, combinando, modificando e criando algo novo. A combinação desses elementos e ações - personagens e ações - já representa algo autoral. Para Vigotski (2009), é essa capacidade de fazer uma construção de elementos, de combinar o antigo de novas formas, que constitui a base de toda atividade criadora. Verifiquemos o trecho seguinte:

Chegando a fazenda do xerife ele ajudou a bela camponesa a descer de seu cavalo e lhe perguntou:

Como é seu nome, ela respondeu:

Meu nome é Mariana e o seu xerife?

O meu é Guilherme, ela perguntou ao xerife:

Revista Devir Educação, Lavras, vol.2, n.1, p.83-102, jan./jun., 2018. 


\section{Q DEVIR EDUCAÇÃO}

ISSN: 2526-849X

O senhor poderia me levar para casa?

Claro que sim vamos! Montaram no cavalo e foram chegando a casa da moça e desceu-a deram tchau um para o outro e o xerife voltou a fazenda tirou a sela de seu cavalo guardou-a e entrou dentro de casa tomou um banho, jantou e foi dormir.

Aqui a riqueza de detalhes, o diálogo entre as personagens e a forma como os autores narram deixam evidente suas marcas de autoria. De acordo com Vigotski (2009), neste gênero de atividade, ou seja, na atividade criadora ou combinatória, o aluno é capaz de escrever algo novo, pois o cérebro combina e reelabora de forma criativa novas ideias e novas imagens.

Analisemos outro trecho a seguir. Nele identificamos indícios de autoria, ao produzirem a ação da personagem principal que deu uma carona a cavalo até o seu serviço.

No dia seguinte o xerife foi andar a cavalo e encontrou a bela camponesa e lhe deu uma carona a cavalo até o seu serviço.

Depois de alguns dias o xerife teve que viajar mas ele não conseguia esquecer a camponesa.

Quando ele voltou e foi direto a casa da camponesa bateu na porta e convidou-a para ir a fazenda ela disse que ia chegando la ele lhe pediu em casamento. Depois de uns meses eles casaram e viveram felizes em sua fazenda.

No fragmento do conto produzido pela dupla Mauricio e Maria Alice, também, identificamos indícios de autoria. Vejamos o trecho a seguir.

Um dia bem frio em Flerijord, uma guerra começou.

Os ninjas de gelo lutaram, mas só um sobreviveu. Ele se chamava Iasuo. Ele era valente, forte e inteligente. O rei foi a guerra e morreu, sua mulher não aceitou isso e virou uma ninja, seu nome era Ashe.

Um ano se passou e ela é profissional em todas armas gélidas, principalmente, seu arco.

Sua filha começou a aprender artes marciais com a mãe.

Uma nova guerra começa, os magos de fogo e ninjas de fogo vão para guerra para conquistar o reino de Flerijord.

Observamos que a dupla de autores traz as vozes dos jogos online. O conto é inspirado em um dos games gratuitos mais jogados do mundo, o League of Legends que consegue misturar uma jogabilidade simples com uma temática popular entre crianças e adolescentes. O jogo possui vários cenários com batalhas emocionantes e estratégias calculadas. 
Os autores escolhem a história de um jogo online para marcar a autoria, refratando uma voz social, ou seja, assumem uma posição que poderíamos caracterizar como a de um sujeito autor que vê nos jogos da Internet a possibilidade de transformar esse enunciado alheio em seu próprio enunciado. Ao assumirem os enunciados alheios e seus próprios enunciados, os alunos demonstram serem sujeitos repletos de palavras interiores, que têm voz e que a explicitam. Para Bakhtin (1997) todo texto dialoga com outros textos, em uma dinâmica permanente da cadeia enunciativa dos dizeres sociais e históricos.

Passamos à análise de um rascunho de conto produzido pelos alunos Augusto e Karine. Trouxemos para análise o roteiro do rascunho e não o conto produzido. Isso se deve ao fato dos autores não explicitarem no conto algumas características que apareceram somente no roteiro. Observemos o roteiro do rascunho.

\author{
Tempo - a tarde \\ Lugar-Praia de Cancum \\ Elemento mágico - Uma pedra de Rubi \\ Personagens - Caio Castro, Taylor Swift, Renato Jonequine e Demi Lovato. \\ Características - Caio policial, Taylor cantora, Renato ator, Demi cantora. \\ Desfecho (final) - [os alunos não escreveram aqui no roteiro] \\ (Augusto e Karine).
}

Verificamos que a dupla de autores traz as múltiplas vozes das telenovelas brasileiras e mexicanas, bem como das cantoras americanas. Para Bakhtin (1997), o discurso se constrói por meio de diferentes graus de alteridade das palavras do outro, são as diferentes vozes que se realizam pelos modos de expressar e pelos sentidos que se materializam na enunciação. Assim, as vozes dos outros se fundem à voz do sujeito que enuncia no texto. Observamos que o elemento mágico, “a pedra de Rubi” e o lugar onde se passa a história, “a praia de Cancun”, remetem à telenovela mexicana Rubi, produzida pela Televisa e exibida pelo Sistema Brasileiro de Televisão (SBT). Verificamos também que personagens como "Caio Castro" e "Renato Jonequine" são atores que atuam na teledramaturgia brasileira.

O fragmento de conto que se segue traz elementos da mídia, ao incorporarem personagens de clips de artista para recriar novas formas de compor essas personagens no conto produzido.

Eu quero um lindo show perfeito.

E foi o dia da festa e a Demi e Taylor fizeram o show e a Taylor cortou au meio a pedra de rubi e mandou fazer dois colares para ela e pra Demi.

Revista Devir Educação, Lavras, vol.2, n.1, p.83-102, jan./jun., 2018. 
Verificamos neste fragmento do conto, a influência das cantoras americanas Taylor Swift e Demi Lovato que dão nomes às personagens. Estas duas cantoras têm como público alvo os adolescentes. Sabemos ainda que são cantoras famosas por seus clips, em que, eventualmente, apresentam em seus shows usando roupas caras e muitas joias.

O fragmento de conto que se segue foi produzido pelos alunos Eduardo e Renata. Verificamos que a dupla de autores não se apropriou das características do conto maravilhoso e migrou para o conto de fadas. Vejamos o trecho a seguir.

Em uma bela manhã em um campo florido lá estava a fadinha Vitória, se arrumando para sair... de repente chegou o Dinossauro Eduardo e deu um baita susto nela então, ela disse:

_ Eduardo o que você veio fazer aqui no meu castelo?

_ Eu vim te convidar para pegar flores na floresta. Você aceita?

- Mas é claro vamos!

Os dois saíram para buscar as flores, então encontraram uma trilha de doces e seguirão em frente passou alguns minutos e acharam uma casa de doce em construção e ficaram tão entusiasmados que em um piscar de olhos já tinha comido todos os doces de repente chegou a bruxa [...]

Ao escolher as personagens bruxa e fada, verificamos que são personagens de conto de fadas. Referindo-se a uma casa de doces e a uma trilha no meio da floresta, o texto faz lembrar o conto de fadas "João e Maria". Ao adotar uma estratégia de incorporação das vozes alheias a partir da inserção "de uma casa de doces no meio da floresta", o texto nos remetendo a elementos do conhecido conto. Os autores reproduzem a cena em que as personagens se perdem na floresta e são pegos pela bruxa, mas essa reestruturação traz um elemento novo, a bruxa era boa e os ajuda a voltarem para casa. Além disso, eles seguem uma trilha e descobrem que esses doces eram mágicos.

\section{Algumas considerações finais}

Dos quinze contos produzidos pelos alunos, pudemos verificar que foram criados seis contos maravilhosos, sete contos de fadas e dois contos que não se encaixaram nessa classificação. Os contos maravilhosos se mesclam aos contos de fadas nas produções dos alunos, provavelmente, porque são identificados como se tivessem a mesma natureza, como nos esclarece Coelho (1987). Segundo, porque o gênero textual conto de fadas está mais 


\section{OD DEVIR EDUCAÇÃO}

ISSN: 2526-849X

presente na escola, é o modelo geralmente escolhido para realizar atividades de produção textual.

Ao elaborarem os contos, os sujeitos da pesquisa evidenciaram em seus enunciados tanto a reprodução como a criação, bem como a reestruturação de outros dizeres. Demonstraram, portanto, as vozes que permeiam a interlocução existente na esfera cultural em que estão inseridos, comprovando que a autoria também se dá na inter-relação do seu dizer com o dizer de outrem.

Sabemos também que para desenvolver a constituição autora é preciso ver as produções dos alunos não como reproduções de ideias alheias, mas como produtos de expressão de subjetividades, pois retomando Bakhtin (1997), entendemos a autoria relacionada a uma postura do sujeito que ao assumir responsivamente sua enunciação na escrita, deixa nela seus pontos de vista, ideologias, crenças e valores.

Assim, podemos afirmar que são diversas as estratégias que podem ser adotadas para um enunciador constituir-se autor. É tarefa de a escola identificar e utilizar as ferramentas adequadas no trabalho com a produção escrita, para o desenvolvimento das estratégias de enunciação que caracterizam as práticas discursivas tendo em vista a formação autora de seus alunos por meio da produção de narrativas escritas, com base no gênero textual conto.

\section{Referências}

BAKHTIN, Mikhail. Estética da Criação Verbal. 2 ed. São Paulo: Martins Fontes, 1997.

GERALDI, João Wanderley. Linguagem e ensino: exercícios de militância e divulgação. Campinas, SP: Mercado de Letras - ALB, 1996.

LEONTIEV, Alexis Nikolaevich. Uma contribuição à teoria do desenvolvimento da psique infantil. In: VIGOTSKI, Lev. Semenovich; LURIA, Alexander Romanovitch; LEONTIEV, Alexis Nikolaevich. Linguagem, desenvolvimento e aprendizagem. São Paulo: Ícone, 1988.

. O desenvolvimento do psiquismo. 2 ed. São Paulo Centauro: 2004.

SCHNEUWLY, Bernard; DOLZ, Joaquim. Gêneros orais e escritos na escola. 3 ed. Campinas: Mercado de Letras. 2011.

VYGOTSKI, Lev Semenovich. A Formação Social da Mente. $6^{\text {a }}$ ed. Tradução de José Cipolla Neto, Luis Silveira Menna Barreto, Solange Castro Afeche. São Paulo: Martins Fontes, 2000. 
VYGOTSKI, Lev Semenovich. Obras Escogidas II. Madri: Visor, 2001. . Imaginação e criação na infância. São Paulo: Editora Ática, 2009. 2010. . A Construção do pensamento e da linguagem. $2^{\mathrm{a}}$ ed. São Paulo: Martins Fontes, 